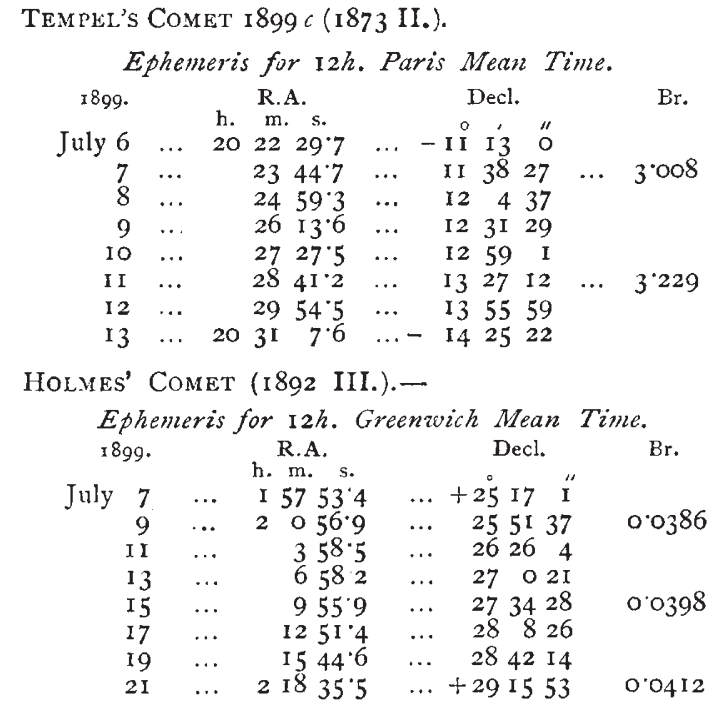

Maxima of Mira.-Mr. A. A. Nijland, of Utrecht, communicates to Astr. Nach. (Bd. 149, No. 3576) an account of his observations of Mira during the apparition in 1898 . During the period extending from August 9, 1898, to March 5, 1899 , sixty-one observations of magnitude were obtained. The light curve being plotted from these gives the time of maximum as October 4, I898, this being very close to the predicted time given by Chandler in his third catalogue. The following table shows the observed and calculated times of the last three maxima :-

\begin{tabular}{|c|c|c|c|c|}
\hline $\begin{array}{l}\text { Observed } \\
\text { maximum. }\end{array}$ & $\begin{array}{c}\text { Calculated } \\
\text { Chandler III. }\end{array}$ & $\begin{array}{c}\text { Retard- } \\
\text { ation. } \\
\text { Days. }\end{array}$ & $\begin{array}{l}\text { Magni- } \\
\text { tude. }\end{array}$ & $\begin{array}{c}\text { Period. } \\
\text { Days. }\end{array}$ \\
\hline $97 \mathrm{Ja}$ & I 896 Dec. I 3 & 29 & 370 & \\
\hline 97 Nov. 26 & I 897 Nov. 9 & 17 & $3 \cdot 24$ & $\begin{array}{l}319 \\
312\end{array}$ \\
\hline 98 Oct. 4 & I898 Oct. 6 & -2 & $2 \cdot 91$ & \\
\hline
\end{tabular}

The New Algol Variable in Cygnus. - Harvard College Observatory Circular (No. 44) contains the results of a detailed examination of all the Draper memorial plates covering the region of the variable star $\mathrm{BD}+45^{\circ} 3062$, discovered by Mdme. Ceraski at Moscow (see NATURE, vol. lx. p. II4). Altogether I95 plates show the star, on 170 of which it is at its full brightness, while 20 show it below its normal magnitude. A full discussion of these plates resulted in the determination of the period of the variable to be

$$
4 \text { d. } 13 \text { h. } 45 \mathrm{~m} \text {. } 2 \mathrm{~s} \text {. }
$$

It is noticeable that the variation in brightness of this star amounts to about three magnitudes, and therefore exceeds that of any Algol star hitherto discovered. Like all other Algol stars, its spectrum is of the first type. A table showing the times of minima for the remainder of the year is included in the Circular.

\section{THE HOUSING OF THE OFFICES OF THE UNIVERSITY OF LONDON.}

THE history of the negotiations which have taken place between the Government and the Senate of the University of London, relating to the proposal of the Government to provide accommodation for the University in the Inperial Institute building, is contained in the subjoined extracts from the Report of the Special Committee appointed by the University to confer with representatives of the Treasury and of the Imperial Institute upon the matter.

At a meeting of the Senate held on December 7,1898 , a letter from Sir Francis Mowatt to the Vice-Chancellor (Sir Henry Roscoe) was read, stating that it had been suggested to the Cabinet that an arrangement might be possible by which an adequate and dignified home for the University of London could be provided in the Imperial Institute buildings, subject to some extension and internal alterations, if terms could be offered which would be acceptable to the authorities of the Institute.

The terms submitted to the Senate of the University are as follows :-

"The Government will provide adequate and suitable accommodation for the University of London, as constituted by the Act of last Session, in the buildings of the Imperial Institute, such accommodation to include examination rooms and laboratories either in the building itself or in a new building to be erected immediately aujjoining it.

"The Government will undertake the entire cost of the upkeep and maintenance of the buildings, including their protection from fire.

"The works necessary for providing the accommodation in the Institute buildings, corresponding to that now enjoyed by the University in Burlington Gardens-and including the new laboratories-will be put in hand at once; and the head. quarters and offices of the University, as at present constituted, will be transferred from Burlington Gardens as soon as possible after the new accommodation is ready for their reception.

" The accommodation in the Institute buildings required for the teaching side of the University will be prepared in anticipation of the date at which the provisions of the Act of last Session come into full operation.

"A Committee consisting of representatives of the University, the Treasury, and the First Commissioner of Works, should be appointed forthwith to inquire and report as to the necessary alteration and adaptation of the Institute buildings for the purposes of the University."

After a brief statement of the scope and object of this offer, the discussion upon the proposals was adjourned. There seemed to be some uncertainty in the minds of certain of the Fellows as to the precise terms upon which the proposed joint occupation of the buildings of the Imperial Institute were to be arranged as between the Government on the one hand and the University and the Imperial Institute on the other. It was felt that if a statement could be made upon certain points raised in the discussion such statement would be of signal service in clearing away any misapprehension which might have arisen. The following inquiries were therefore sent to Sir Francis Mowatt, and, with the replies, were read at a meeting of the Senate on February I :-

"I. Is it to be understood that the Government proposes to take over the whole of the present building of the Imperial Institute for the use of $(a)$ the University of London, $(b)$ the authorities of the Imperial Institute?

" 2 . Will the University (in case the proposals are carried out) be the tenants of the Government under identical conditions as to fixity of tenure, maintenance, \&c., as heretofore in Burlington Gardens?

" 3 . Is it understood :

"(a) That the University will become possessed for its sole use of so much of the Institute buildings as the Government shall decide, after communication with the University of London, to be sufficient for its present and prospective accommodation?

" (b) That the University shall have the first use of such halls, corridors, galleries, as are necessary for carrying on its work of examination?

"(c) That all concerts and other entertainments in the Institute are to be abolished ?

"(d) That a suitable entrance to the University portion of the building will be provided after due communication with the architect?

"(e) That all educational work of University character carried on within such portion of the building handed over to the Institute authorities shall be under the direct control of the University?

" $(f)$ That proper accommodation will be provided for the University examinations in practical science either in the Imperial Institute buildings or in others to be built outside as may be decided on after further discussion?"

The reply, dated Christmas Day 1898 , was as follows:-

"It is not the intention of the Government that any of the three parties should enter on the proposed inquiry with their hands tied. Their sole wish is that the University, the Institute, and the Treasury should meet and discuss whether any, and, if any, what arrangement is possible, under which the University could be suitably housed, and under suitable conditions, in the

$$
\text { NO. I } 549 \text {, VOL. 6o] }
$$


present Institute buildings. If the result of the discussion is to show that no suitable arrangement is practicable, the University will be in no way prejudiced by having shown its readiness to discuss the project in a friendly spirit. It will be quite open to the Senate to make an express reservation in the above sense a condition of sending its representatives to sit on the Committee.

"The answer to the first and second questions is yes.

"As regards the third, the answers are-

"(a) Yes.

" (b) I am not sure that I quite understand the meaning of the words 'the first use,' but if the following definition will meet the views of the Senate, I can answer the question in the affirmative, viz. "Full and exclusive use and control at all times at which the said halls are required for the purposes of examination.'

"The regulations for giving effect to this condition will be drawn up by the Treasury, who will be responsible for seeing that they are carried out.

" (c) The representatives of the Institute have assured me that the entertainments and concerts will not again take place, but it will be quite open to the Senate to safeguard themselves by making the discontinuance of such things a condition of their presence on the Committee.

"The answers to $(d),(e)$ and $(f)$ are in the affirmative."

The views of Convocation upon the proposals are contained in the following letter from the Clerk of Convocation to the Registrar, read at the meeting of the Senate :--

"I am directed by the Special Committee of Convocation, appointed to communicate with the Statutory Commission and the Senate, to request you to inform the Senate that the Committee having had their attention directed to the subject of the proposed transference of the University to the Imperial Institute, adopted the following resolution:-

"That, in the opinion of this Committee, the Imperial Institute would furnish an adequate and dignified home. for the University, provided that the exclusive and permanent control of the whole or a distinct and sufficient portion, with an adequate entrance, and with security of tenure, be vested in the University."

On the motion of the Vice-Chancellor, seconded by Lord Kimberley, it was then resolved:

"That with reference to the correspondence between the Vice-Chancellor and Sir Francis Mowatt, the Senate do agree to join in the Conference therein mentioned upon the terms generally set forth in the correspondence, and without prejudice to the ultimate action of the Senate, and that accordingly three Fellows be nominated as a Special Committee of the Senate to serve on the Conference, and to report to the Senate the result of the Conference."

The following Fellows were nominated Members of the Special Committee :-The Vice-Chancellor, Lord Kimberley, and Sir Joshua Fitch.

At the next meeting of the Senate, on February 22, further correspondence was presented. It was announced that the Lords Commissioners of Her Majesty's Treasury had selected the undermentioned gentlemen to represent them at the Conference :- -

Sir F. Mowatt and Mr. S. E. Spring Rice, both of the Treasury, and Mr. Almeric Fitzroy, Clerk of the Council.

The following Treasury Minute, dated February 16, I899, was read :-

"The First Lord and the Chancellor of the Exchequer state to the Board that Her Majesty's Government have had under consideration the possibility of an arrangement with the authorities of the Imperial Institute whereby a dignified and suitable home may be provided in the Institute buildings at South Kensington for the University of London, as reconstituted by the Act of last Session. The accommodation would include the sole occupation and control of rooms and offices fully equal in number and dimension to those now in the possession of the Senate at Burlington Gardens; examination rooms and laboratories either in or immediately adjoining the existing building; and also such provision as may hereafter be needed for the full extension and development of the University under the statutes and regulations made by the Commissioners appointed by the Act.

"The First Lord and the Chancellor of the Exchequer state that, as the result of negotiations which have taken place between representatives of the University, the Institute and the Treasury, there is reason to hope that an arrangement meeting all the requirements of the several interests is now possible; and they recommend to the Board that the authorities of the University and the Institute should be invited to nominate representatives, who will consider and report in conference with persons selected by the Treasury-

"I. Whether such an arrangement is in fact practicable.

"II. What is the amount and nature of the accommodation to be transferred.

"III. What alterations or adaptations are necessary to render it in all respects suitable to the needs of the U niversity.

"IV. Under what conditions it should be held from IIer Majesty's Government by the Senate.

"The object of the Conference would be expressly limited to furnishing Her Majesty's Government with full inform ation upon the several points indicated above; and the consent of the several parties to enter the Conference would not pledge them to accept any recommendation which the represent atives, or a majority of them, may make.

"My Lords approve the course recommended by the First Lord and the Chancellor of the Exchequer."

The representatives of the Council of the Institute appointed to take part in this Conference were Lord James of Hereford, the Right Hon. Sir Henry Fowler, M.P., and Sir Frederick Abel.

The Conference thus constituted held several meetings at the Treasury and at the Institute, and the Committee paid repeated visits to South Kensington with a view to ascertain the exact extent and capabilities of the building, particularly of that porion of it which it is proposed to assign to the University.

On the first of these occasions the Prince of Wales met the Committee and accompanied the members through the various rooms of the Institute. His Royal Highness evinced much interest in the proposed arrangement, and expressed a strong wish to meet the requirements of the Senate and to facilitate the work and due development of the University.

At a subsequent meeting the representatives of the University were requested to draw up, for the information of their col. leagues, a statement showing the nature of the accommodation needed by the University, and also the way in which the eastern portion of the building might be adapted to the use and to the future requirements of the University. In conformity with this wish the Committee prepared a memorandum, which became the basis of discussion at subsequent meetings of the Conference.

Among the points referred to in this document are the future requirements of the University. Upon this subject the representatives of the University remark :

"In considering the proposal to exchange the present building in Burlington Gardens for a portion of that now occupied by the Imperial Institute, it is necessary not only to take into account the means of supplying these serious deficiencies, but also to forecast the probahle requirements of the University under its new constitution. The details of that constitution are now being settled by the Statutory Commission appointed under the provisions of the University of London Act of 1898 .

"The new statutes will certainly provide for a large extension in the work and usefulness of the University, will invest it with new teaching powers, will bring it into closer relations with the principal colleges and medical schools of the metropolis, and will, without encroaching on the ordinary functions of those institutions, probably do much to encourage the development of post-graduate study and of research, under the direction of the governing body of the University, and in its central building."

With regard to the central portion of the building, the memorandum states :-

"It is evident that joint user of this neutral territory, on the part of the Institute and the University, would be for many reasons inconvenient unless the relations and claims of the two bodies are clearly defined. Otherwise frequent references to the Treasury would become necessary.

"Moreover. it is essential for the credit and for the usefulness of the metropolitan University that it should not be regarded as, in any sense, a department of another institution. It would cause grave disappointment to the Senate and to the Graduates if we were unable to report to them that the Government were sensible of the importance of this consideration, and able to give effect to it.

"It is obviously desirable that the building to be known as the University of London should have a separate entrance."

NO. I 549, VOL. 60] 
It was in relation to the neutral territory referred to that the representatives of the University felt it necessary to receive further explanations. It was at first proposed by the authorities of the Institute that a joint permanent Committee should be formed, and that while the University and the Institute respectively should be entitled to have the use of the central hall and the east conference hall on certain occasions to be specified beforehand, the occupation of the rooms on other occasions should be settled by arrangement with this Committee. But grave inconvenience and the possibility of future complications were foreseen in such an arrangement. From the first it had been impressed upon the Treasury that the relations of the University should be with the Government alone, and that any plan which assumed that the University should be either tenants or partners with another institution would certainly be un welcome to the Senate. The Committee therefore insisted that, in accordance with the letter of Sir Francis Mowatt of Christmas Day I 898, the University should be the tenants of the Government only. As a result the following formal communication, lated May 16 , was received by the Vice-Chancellor from Sir Francis Mowatt :-

"With reference to our recent discussions as to the conditions on which the Government is prepared to offer to the University improved and enlarged accommodation in the Imperial Institute building, I am authorised by the Chancellor of the Exchequer to inform you that the original intention of the Government remains unchanged, namely, to take over all the present building for the use of $(a)$ the University of London, and $(b)$ the authorities of the Imperial Institute, and that he has caused notification to this effect to be communicated to the Council of the Institute.

"I am at the same time instructed to forward to you the enclosed memorandum indicating that the University will hold direct from the Government."

The memorandum enclosed was as follows :-

"In any arrangement under which the University is invited to occupy a part of the Institute building, it will be an absolute condition that the University holds directly and solely from the Government and not in any form or degree from the Institute.

"This is true equally of the part to be occupied exclusively by the University and of the part to be occupied alternately by the University and by the Institute under arrangements to be approved by the Treasury."

The exact nature of the arrangements here referred to between the University and the Treasury, with respect to the central portion of the building, the galleries, and the east conference hall, will be fixed from time to time on the understanding that the full and exclusive use of these portions of the building will be secured for the University at all times at which they are required for purposes of examination, for the annual ceremony of the presentation for degrees, and for the meetings of Con vocation. The Senate will also afford, as it has been accustomed to do during many years, accommodation to meetings and congresses of a national and international character, as well as for assemblies of graduates or others interested in the promotion of collegiate or advanced education.

Subject, therefore, to any reservation which the Treasury may make as to the use of the central portion of the main building for occasional meetings of the Imperial Institute, the building, with the exception of the west wing, will either belong exclusively to the University or will be at its disposal when required. The main entrance will be used by the University and by the Imperial Institute jointly. An additional University entrance and staircase will give access to the east wing, and will serve for candidates for examination and for other purposes.

The assent of the Council of the Imperial Institute to the Government proposals was notified in a letter dated June 5 from Lord James of Hereford to Sir Francis Mowart.

With regard to the future appropriation of land adjacent to the building, it is understood that, in view of the probable future requirements of the University, especially in the direction of scientific and literary research and of post-graduate lectures and studies, the University will be entitled to a first claim on any vacant ground which may hereafter prove to be needed. The area thus available is very large.

It is understood that the Government is prepared to undertake the whole cost of the removal of the effects of the University to its new quarters, and that the Chancellor of the Exchequer will include in the estimates for this year a sufficient sum to meet all charges for furnishing the rooms, for adapting them to the purposes of the University, and also for effecting such structural and other changes as may be found necessary in subsequent consultation between the officers of the University and the architect of the Board of Works. At present no change is proposed in the financial arrangement by which the charges of the University for the maintenance and care of the build ing, the provision of stationery and stores, the salary of the officers, and the expenses of administration are borne by the Treasury, and are provided, so far as they exceed the amount received from candidates in the form of fees, by an annual vote in Parliament.

This arrangement is, however, wholly exceptional, and does not apply to any other University in Great Britain. It undoubtedly relieves the authorities of the University from all financial concern or responsibility. But it cannot be regarded as a permanently satisfactory settlement, or one which is likely to conduce to the repute and independence of the University, or to its due development in the future. It has the obvious and serious result of discouraging endowments and gifts, and of diminishing the interest which the inhabitants of London ought to take in their chief academic institutions. So long as the University is dependent for its maintenance on an annual vote in Parliament, it can hardly be expected to receive much voluntary support. Such generous gifts from private persons or from municipal bodies as have enriched the colleges of the Victoria University, and have recently been promised to the contemplated University of the Midlands, are not likely to be forthcoming in London while the University exists on its present financial basis. But it may well be hoped that under different conditions the University will evoke similar local patriotism to that which has been so conspicuously shown in Manchester, Liverpool, Leeds, Cardiff, Newcastle and Nottingham, and that the citizens of London will become conscious of a new responsibility, and will take a pride in strengthening and enlarging from time to time an institution which ought to serve as a great centre of intellectual life for the whole metropolis.

The Government has throughout this negotiation shown a strong desire to make the best provision in its power to meet the needs of the University and the wishes of the Senate and the Graduates. And, having regard (I) to the fact that the present accommodation is insufficient, and that there are no means of enlarging it upon its present site ; $(2)$ to the size and dignity of the Institute building and its capacity for adaptation and expansion ; $(3)$ to the fact that no alternative proposal for the housing of the University in a more appropriate place is likely to be made; and (4) to the consideration that the building, though not geographically central for London, is placed in the midst of a group of institutionsthe Royal College of Science, the Natural History Museum, the City and Guilds of London Institute, the College of Music, and the Science and Art Galleries and Museums-which are all in various ways cognate in their objects with the purposes and work of the University, the Committee conclude by expressing the opinion that the proposal of the Government has been conceived in a fair and liberal spirit, and that it deserves the favourable consideration of the Senate.

\section{PHYSTCAL MEASUREMENTS IN ANTHROPOLOGY.}

THE question of the value of physical measurements is one that lies at the base of physical anthropology. Large numbers of often very extended series of measurements are continually being published, new methods are constantly being proposed and tried; but in spite of all this, it is questionable whether the value of the results obtained is proportionate to the trouble expended. Unfortunately there is variability in the methods employed, which may change according to the nationality of the investigators; some methods are complicated like those of Benedikt and Tœrek, or, as in the case of the latter anthropologist, who takes 5000 measurements on a single skull, they may be impracticably numerous. Very precise measurement with refined instruments gives an apparent exacti tude which appears to be more scientific than it really is Preferable is the system that adopts a small number of measurements which can be readily made, and which have a better chance of being taken on a large number of subjects. The 